\title{
Migration and Loss of Phlegmariurus (Lycopodiaceae) at Southern Slope of Mt. Slamet Central Java Indonesia
}

\author{
Pudji Widodo ${ }^{1}$ and Titi Chasanah ${ }^{2}$ \\ ${ }^{1}$ Universitas Jenderal Soedirman \\ ${ }^{2}$ Universitas Jenderal Soedirman Fakultas Biologi
}

November 27, 2020

\begin{abstract}
Phlegmariurus is a genus of lycophyte plants in the family Lycopodiaceae which is sensitive to climate change. In the past, there were four species namely 1) Phlegmariurus phlegmaria, 2) P. nummulariifolius, 3) P. carinatus, and 4) P. squarrosus found as epiphytic clubmosses on many trees such as pines and Agathis on the southern slope of Mt. Slamet. During 42 years there has been a significant loss of Phlegmariurus at the slope which covers approximately 15,000 ha rain forest covering the subdistrict of Cilongok in the west, Baturraden in the middle, and Sumbang in the east. Some surveys that had been conducted from 1978 to 2020 showed that the presence frequency of the plant decreased. We correlated the temperature increase data from NOAA and precipitaion data from the local meteorology and geophysics data to the frequency of the plants. Furthermore, we also interviewed ten nurseries which sold the Phlegmariurus of approximately 60 nurseries (Figure 6). The information we gathered showed that the location of the plant sources was above the previous locations. We also observed the cultivated Phlegmariurus at different altitudes namely at 95-97 m, 300-400 m, and 600-800 $\mathrm{m}$ a.s.l. The result of this study showed that in the past there were a lot of Phlegmariurus spp. However, in 2020 Phlegmariurus were absent in most areas at the southern slope of Mt. Slamet. We proposed three causes of the migration and loss of Phlegmariurus at the southern part of Mt. Slamet namely: 1) The increase of temperature, the decrease of precipitation, and 3) commercial hunting.
\end{abstract}

\section{Hosted file}

Pudji.Widodo_Phlegmariurus-20201126.pdf available at https://authorea.com/users/379453/ articles/495648-migration-and-loss-of-phlegmariurus-lycopodiaceae-at-southern-slope-ofmt-slamet-central-java-indonesia

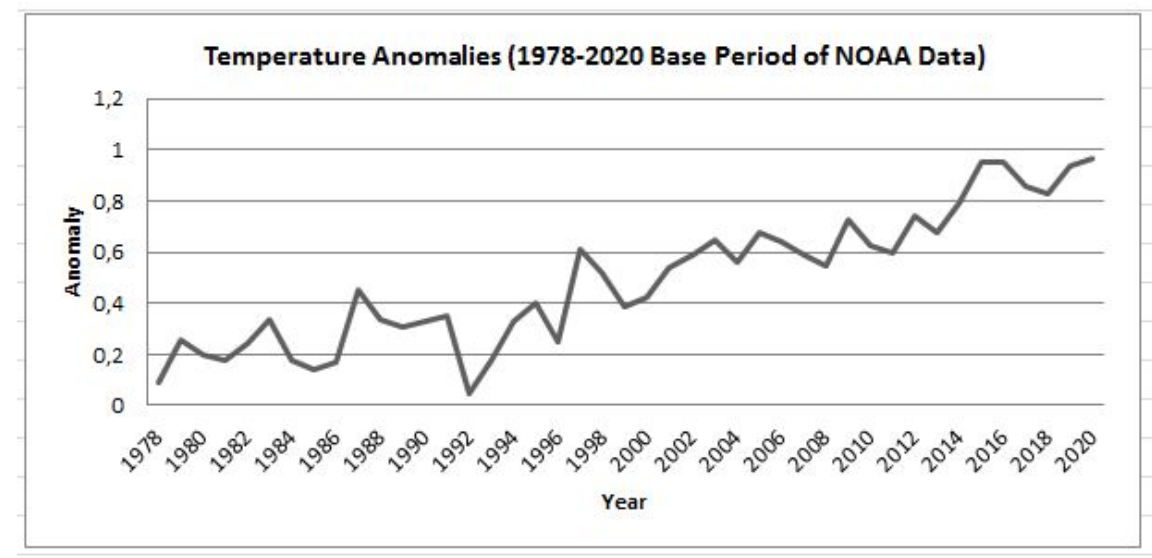



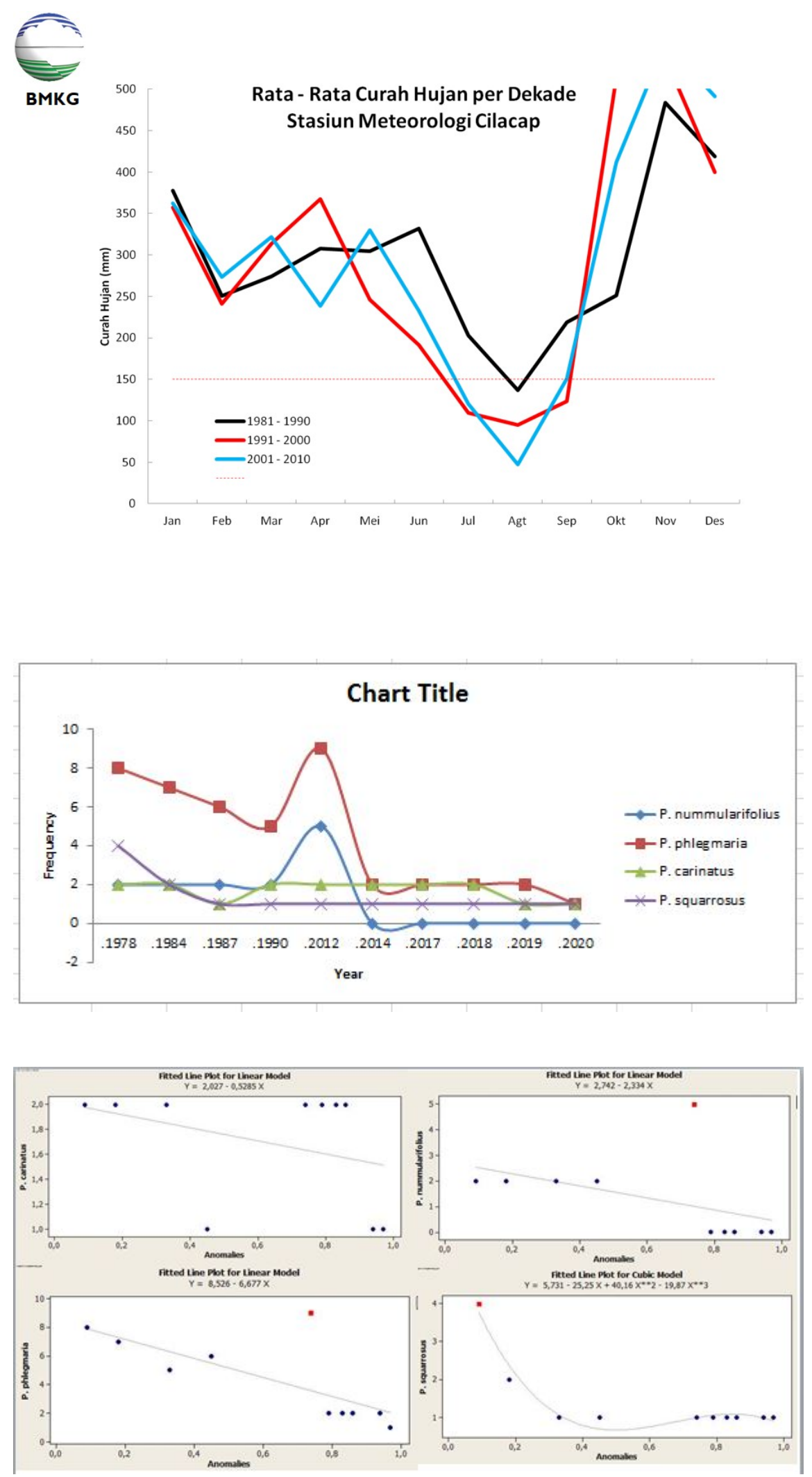

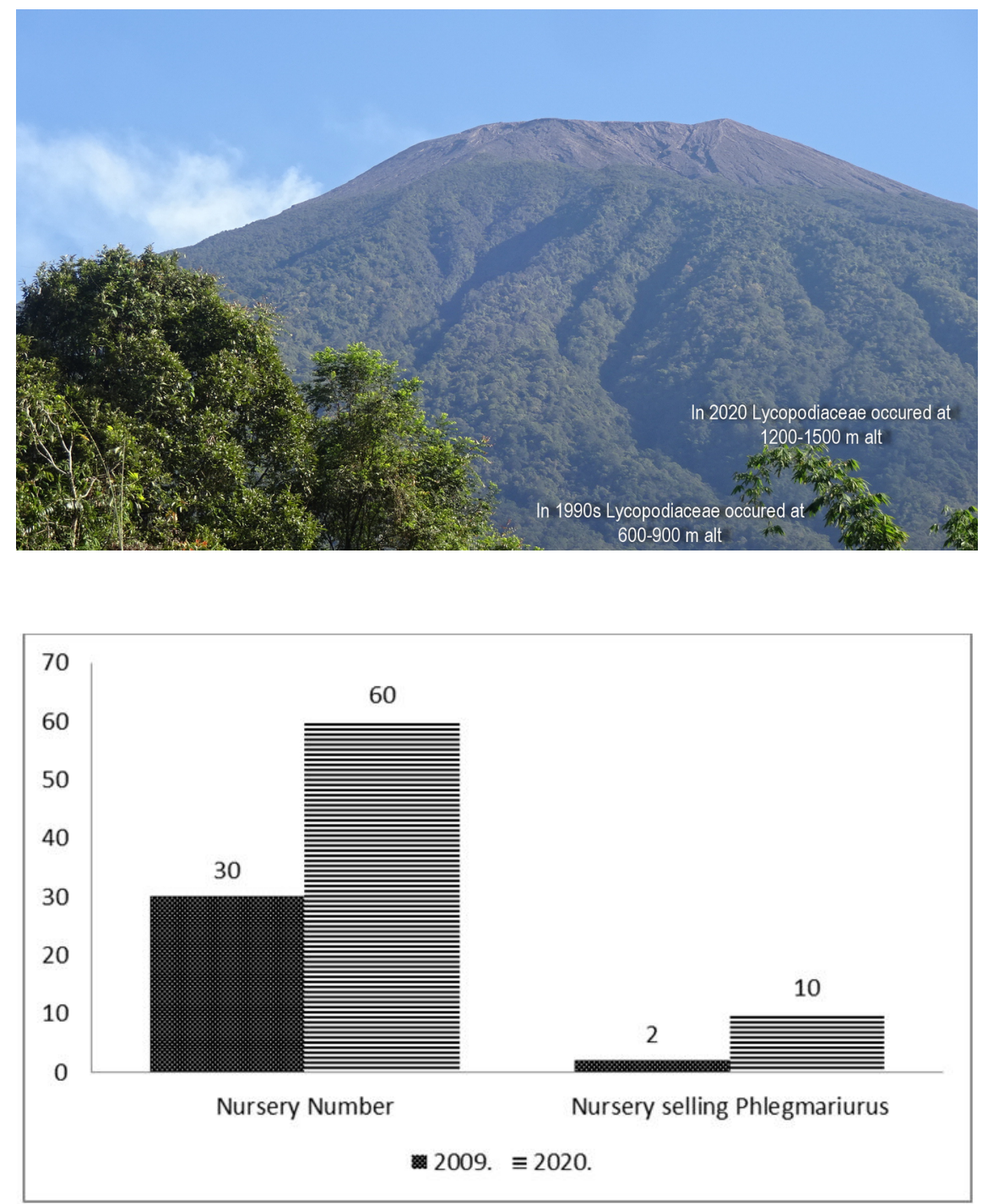

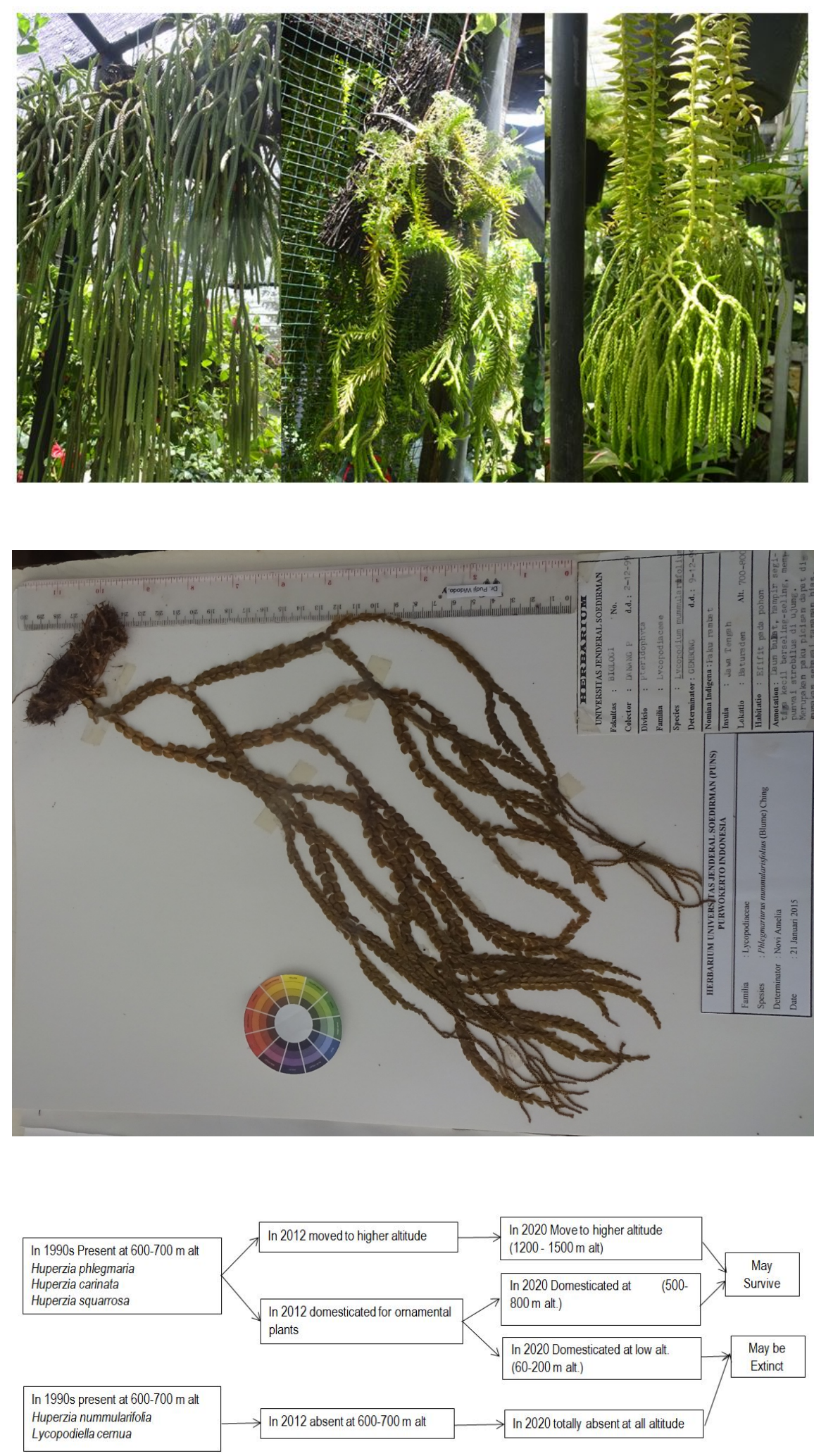